\title{
Analysis of the Sex-Specific Variability of Blood Parameters in C3H Inbred Mice by Using Data From a Long-Term, High-Throughput Project
}

\author{
Bernhard AIGNER ${ }^{1}$, Birgit RATHKOLB ${ }^{1,2,3}$, Martin HRABĚ DE ANGELIS ${ }^{2,3,4}$, \\ Eckhard WOLF ${ }^{1}$
}

${ }^{1}$ Chair for Molecular Animal Breeding and Biotechnology, and Laboratory for Functional Genome Analysis (LAFUGA), Gene Center, LMU Munich, Munich, Germany, ${ }^{2}$ German Mouse Clinic, Institute of Experimental Genetics, Helmholtz Zentrum München, Neuherberg, Germany, ${ }^{3}$ German Center for Diabetes Research (DZD), Neuherberg, Germany, ${ }^{4}$ Chair of Experimental Genetics, School of Life Science Weihenstephan, Technische Universität München, Freising, Germany

Received September 16, 2020

Accepted December 8, 2020

Epub Ahead of Print March 8, 2021

\section{Summary}

Mice are important models for biomedical research by providing the possibility of standardizing genetic background and environmental conditions, which both affect phenotypic variability. Use of both sexes in experiments is strongly recommended because of possible differences in the outcome. However, sex-specific phenotypic variability is discussed with regard to putative consequences on the group size which is necessary for achieving valid and reproducible results. Here, we retrospectively analyzed the sex-specific variability of 25 blood parameters of $\mathrm{C} 3 \mathrm{H}$ inbred mice in two different mouse facilities within the long-term, high-throughput Munich ENU mouse mutagenesis project. Using the $95 \%$ data range, data of 4,780-20,706 mice per parameter were analyzed and resulted in ratios of the coefficient of variation (= female CV / (female CV + male $\mathrm{CV}$ )) from 0.44 to 0.58 for the 25 parameters, with an overall mean of 0.51 in both facilities. Together with data analyses of three additional, smaller studies with 72-247 animals per parameter examined and various genetic backgrounds (inbred strains, F1 hybrids) included, hints for reproducible sex-specific variability were observed for particular parameters. Thus, the overall analysis comprising all 25 clinical chemical and hematological parameters of the standardized, long-term analysis of a high number of group housed, young adult, twelve-week-old $\mathrm{C} 3 \mathrm{H}$ inbred mice showed no evidence for substantial sex-specific variability. The results may provide a basis for the examination of sex-specific variability in particular blood parameters.

\author{
Key words \\ Animal model - Clinical chemistry - Hematology - Sex • \\ Variability
}

\section{Corresponding author}

B. Aigner, Chair for Molecular Animal Breeding and Biotechnology, LMU Munich, Hackerstr. 27, 85764 Oberschleissheim, Germany. E-mail: b.aigner@gen.vetmed.unimuenchen.de

\section{Introduction}

In biomedical research with animal models, use of both sexes is strongly recommended because of possible differences in the outcome (Clayton and Collins 2014, Sandberg et al. 2015). In the context of highly standardized conditions on genetic background and environment used in mouse experiments, sex-specific phenotypic variability is discussed as an experimental factor with putative consequences on the group size for achieving valid and reproducible results. Female hormone cycles are suspected to decrease the homogeneity of study populations and to confound effects of experimental manipulations. In addition, group housing especially of male animals leads to the establishment of a dominance hierarchy and to differences in the social status thereby leading to individual phenotypic variations (Beery and Zucker 2011, Itoh and Arnold 2015,

PHYSIOLOGICAL RESEARCH • ISSN 1802-9973 (online) 
Prendergast et al. 2014, Varholick et al. 2018 and refs. therein).

For nociceptive traits, more than 8,000 individual measurements, collected from 40 different mouse strains in 3 laboratories, showed that females tested at random points in their estrous cycles were not more variable than males (Mogil and Chanda 2005). In a meta-analysis of 293 articles, behavioral, morphological, physiological, and molecular traits were monitored in male mice and females tested without regard to the estrous cycle stage. The variability was not significantly greater in females than males for any endpoint and was substantially greater in males for several traits. In addition, group housing of mice was observed to increase the variability in both males and females by $37 \%$ (Prendergast et al. 2014). In another study, the analysis of 293 microarray datasets measuring gene expression in various tissues of mice and humans, comprising the analysis of more than 5 million probes, showed that on average, male gene expression is slightly more variable than that of females although the difference was small (Itoh and Arnold 2015).

In biomedical research, standardized, long-term, high-throughput analyses of a high number of phenotypic parameters in both sexes of mice have been carried out in phenotype-driven ENU mouse mutagenesis projects worldwide. Random chemical mutagenesis of a large number of animals followed by systematic screening for clinically relevant disease phenotypes was carried out with the alkylating agent $N$-ethyl- $N$-nitrosourea (ENU) which predominantly induces point mutations in premeiotic spermatogonial stem cells. This allowed the production of a large number of randomly mutagenized offspring from treated males, which were used for the establishment of novel mutant mouse lines harbouring disease-related alleles. However, by far most of the offspring showed physiological values for a given phenotype parameter. In the Munich ENU mouse mutagenesis project using $\mathrm{C} 3 \mathrm{HeB} / \mathrm{FeJ}(\mathrm{C} 3 \mathrm{H})$ inbred mice as genetic background, a standardized screening profile of a high number of phenotypic parameters was established for the analysis of offspring of mutagenized mice in order to detect phenotypic variants (Hrabě de Angelis et al. 2000, Hrabě de Angelis et al. 2007).

Here, we retrospectively re-analyzed data from this project, which were formerly used to establish mutant mouse lines, for the new aim to investigate the sexspecific variability of 25 blood parameters in a high number of animals. The blood parameters were chosen for the re-analysis as the data have been collected in our own research group therefore making it possible to track the entire experimental process.

\section{Methods}

\section{Long-term, high-throughput analysis}

Blood parameters were determined in the context of the clinical chemical and hematological screen of the phenotype-driven Munich ENU mouse mutagenesis project by using standardized protocols (Rathkolb et al. 2000a, Rathkolb et al. 2000b). Data were derived over a time period of over six years $(08 / 1998$ $10 / 2004)$ and comprised the analysis of almost 22,000 $\mathrm{C} 3 \mathrm{HeB} / \mathrm{FeJ}(\mathrm{C} 3 \mathrm{H})$ inbred mice (The Jackson Laboratory) housed in two different facilities A and B. They were G1 and G3 male and female offspring derived from ENUmutagenized G0 founder males which were bred by defined breeding schemes (Hrabě de Angelis et al. 2000, Hrabě de Angelis et al. 2007). Up to five mice were housed together in groups of the same sex in Macrolon type II standard cages. Mouse husbandry was carried out under a continuously controlled specific pathogen-free (SPF) hygiene standard according to the FELASA protocols (Nicklas et al. 2002) (http://www.felasa.eu). Mouse husbandry and all tests were carried out under the approval of the responsible animal welfare authority (Regierung von Oberbayern, Germany). Data analysis was carried out using the software program Microsoft Excel 2016 (Microsoft Corp., Redmond, WA). The chisquared test was used for the statistical analysis of the data.

\section{Clinical chemistry and hematology}

The analysis of the clinical chemical blood plasma parameters and the hematological parameters was carried out by standardized protocols as previously described (Gailus-Durner et al. 2005, Rathkolb et al. 2000a, Rathkolb et al. 2000b). Briefly, blood samples from weekly cohorts of twelve-week-old male and female mice were obtained by puncture of the retro-orbital sinus under ether anesthesia. The clinical chemical parameters were analyzed by using the Roche Hitachi 717 autoanalyzer (Roche, Mannheim, Germany) and the adapted reagents for human samples (Roche), and subsequently the Olympus AU400 autoanalyzer (Olympus, Hamburg, Germany) and the adapted reagents for human samples (Olympus) within their linear measurement ranges. Hematological parameters were 
measured using the ABC Animal Blood Counter (Scil, Viernheim, Germany) which was validated by the manufacturer for the analysis of mouse blood. Calibration and quality control were performed daily according to the manufacturer's protocols using the calibration samples obtained from the manufacturers.

\section{Additional non-mutagenized inbred and F1 hybrid mice}

Non-mutagenized inbred and F1 hybrid mice were also used in the context of the Munich ENU mouse mutagenesis project in the studies I, II, and III, which were carried out in three subsequent time periods of two years each in the mouse facilities A or B. The group housed mice for study I were maintained in facility B, and the group housed mice analyzed in studies II and III were maintained in facility A (Klempt et al. 2006). In studies I and II, the inbred strains $\mathrm{C} 3 \mathrm{HeB} / \mathrm{FeJ}(\mathrm{C} 3 \mathrm{H})$ (study I: 85-132 males and 114-115 females; study II: 50-51 males and 79-80 females) and C57BL/6JIco (C57BL/6) (study I: 138-139 males and 72-74 females; study II: 64-71 males and 50 females), and the F1 hybrid mice B6C3F1 (study I: 91-120 males and 89116 females; study II: 39 males and 37-38 females) and C3B6F1 (study I: 90-107 males and 77-94 females; study II: 44-45 males and 38 females) were used. In study III, the inbred strains $\mathrm{C} 3 \mathrm{HeB} / \mathrm{FeJ}(\mathrm{C} 3 \mathrm{H})$ (51-55 males and 39-40 females) and BALB/cJ (BALB/c) (70-82 males and 90-100 females), and the F1 hybrid mice CC3F1 (58 males and 41 females) and C3CF1 (55 males and 61 females) were analyzed (Klempt et al. 2006).

\section{Results}

Long-term, high-throughput analysis of C3H inbred mice

For the analysis of the sex-specific variability of blood parameters in a great number of animals, data from almost 22,000 young adult, twelve-week-old C3HeB/FeJ $(\mathrm{C} 3 \mathrm{H})$ inbred mice derived from the long-term, highthroughput phenotype-driven Munich ENU mouse mutagenesis project were re-analyzed. The project was carried out in two different facilities A and B where G1 and G3 male and female offspring - which were derived from ENU-mutagenized G0 founder males by the use of defined breeding schemes - were examined for clinical chemical and hematological parameters in a standardized procedure (examination of group housed, twelve-weekold animals by standardized protocols) over a time period of six years. By far most of the offspring showed physiological values for a given phenotype parameter.
The data have been previously used for determining mutagenized phenotypic G1 and G3 variants for breeding ENU mutant mouse lines with interesting abnormal phenotypes (Aigner et al. 2009a, Aigner et al. 2009b, Aigner et al. 2011, Klempt et al. 2006, Rathkolb et al. 2015).

As the data were derived from offspring of ENU-mutagenized mice and, therefore, are expected to include a small number of animals harbouring mutations which may alter specific phenotypic parameters, in the current study the $95 \%$ data range (by excluding $2.5 \%$ each of the highest and lowest values) was chosen for each parameter separately to exclude values derived from such mutant mice as well as technical outliers.

The phenotypic variability was analyzed by determining the coefficient of variation $(\mathrm{CV}=$ standard deviation / mean) both for the male and female $\mathrm{C} 3 \mathrm{H}$ mice. A CV ratio (= female $\mathrm{CV} /$ (female $\mathrm{CV}+$ male $\mathrm{CV}))<0.5$ indicates that the female $\mathrm{CV}$ is lower than the male $\mathrm{CV}$, whereas a $\mathrm{CV}$ ratio $>0.5$ indicates that the female $\mathrm{CV}$ is higher than the male $\mathrm{CV}$.

In both facilities $\mathrm{A}$ and $\mathrm{B}, 25$ clinical chemical and hematological parameters in male (facility A: 2,6309,099 mice per parameter analyzed; facility B: 553-3,731 mice) and female (facility A: 1,033-4,452 mice; facility B: 564-3,427 mice) mice were examined (Table 1). Some parameters were analyzed with data from relatively low numbers of animals due to a shorter time period of examination (e.g. ferritin, transferrin, lipase) or because technical procedures changed within the project (calcium, chloride, phosphorus, potassium, sodium, $\alpha$-amylase). In the later case, the subgroup covering the highest number of animals was chosen for the current analysis for the respective parameter. The smaller subgroups were examined separately and mostly showed analogous results compared to the larger subgroups included in the current project (Table 1).

The $\mathrm{CV}$ ratios ranged from 0.44 to 0.58 in facility A with $\mathrm{CV}$ ratios $<0.5$ (= lower female $\mathrm{CV}$ ) for $\mathrm{n}=9$ of $25(36 \%)$ parameters, and ranged from 0.47 to 0.56 in facility $\mathrm{B}$ with $\mathrm{CV}$ ratios $<0.5$ (= lower female $\mathrm{CV})$ for $\mathrm{n}=10$ of $25(40 \%)$ parameters. For both facilities, the chi-squared test showed no significant difference $(p>0.05)$ of the detected counts of parameters with a $\mathrm{CV}$ ratio $<0.5$ and a $\mathrm{CV}$ ratio $>0.5$ compared to the hypothesis of equal numbers of parameters with a $\mathrm{CV}$ ratio $<0.5$ and a $\mathrm{CV}$ ratio $>0.5$. Consistent $\mathrm{CV}$ ratios (either $\mathrm{CV}>0.5$ or $\mathrm{CV}<0.5$ ) in both facilities were observed for 16 of 25 (64\%) parameters (11 of 25 with 
Table 1. Coefficient of variation ratios (= female CV / (female CV + male CV)) of the blood parameters of C3H mice in the Munich ENU mouse mutagenesis project ( $95 \%$ data range)

\begin{tabular}{|c|c|c|c|c|}
\hline Parameter & $\begin{array}{c}\text { CV ratio, facility } \\
\text { A }\end{array}$ & $\begin{array}{c}\text { CV ratio, facility } \\
\text { B }\end{array}$ & $\begin{array}{l}\text { No. of mice }(\mathbf{m} / \mathbf{f}) \text {, } \\
\text { facility } A\end{array}$ & $\begin{array}{l}\text { No. of mice }(\mathbf{m} / \mathbf{f}) \text {, } \\
\text { facility } B\end{array}$ \\
\hline Cholesterol & 0.54 & 0.53 & 6387 / 3362 & $3181 / 2860$ \\
\hline Creatinine & 0.51 & 0.499 & 8965 / 4379 & 3703 / 3398 \\
\hline Glucose & 0.504 & 0.52 & 8968 / 4385 & 3704 / 3397 \\
\hline Total protein & 0.497 & 0.52 & 9033 / 4398 & 3708 / 3401 \\
\hline Triglycerides & 0.58 & 0.56 & $6373 / 3364$ & $3179 / 2859$ \\
\hline Urea & 0.53 & 0.53 & $9003 / 4395$ & 3704 / 3401 \\
\hline Uric acid & 0.51 & 0.54 & 6475 / 3402 & $3185 / 2877$ \\
\hline Ferritin & 0.497 & 0.48 & 3029 / 1180 & 669 / 666 \\
\hline Transferrin & 0.51 & 0.51 & 5325 / 2201 & $1351 / 1311$ \\
\hline Calcium & 0.51 & 0.48 & $3515 / 2130$ & $2321 / 2061$ \\
\hline Chloride & 0.52 & 0.52 & 3515 / 2134 & $2324 / 2064$ \\
\hline Phosphorus & 0.51 & 0.49 & $3515 / 2133$ & $2324 / 2063$ \\
\hline Potassium & 0.505 & 0.503 & 3515 / 2135 & $2324 / 2065$ \\
\hline Sodium & 0.48 & 0.51 & $3514 / 2135$ & $2324 / 2064$ \\
\hline$A L T$ & 0.44 & 0.48 & 9094 / 4451 & $3731 / 3426$ \\
\hline$A S T$ & 0.504 & 0.48 & 9099 / 4452 & $3728 / 3427$ \\
\hline$\alpha$-amylase & 0.54 & 0.53 & 5575 / 2296 & $2324 / 2060$ \\
\hline$A P$ & 0.52 & 0.47 & 7195 / 3719 & 3494 / 3184 \\
\hline$C K$ & 0.49 & 0.47 & $6432 / 3414$ & 3199 / 2878 \\
\hline Lipase & 0.45 & 0.49 & $2630 / 1033$ & $553 / 564$ \\
\hline Hemoglobin & 0.51 & 0.504 & $6173 / 3263$ & 3337 / 3040 \\
\hline$M C V$ & 0.48 & 0.51 & $6175 / 3263$ & $3337 / 3040$ \\
\hline$R B C$ & 0.51 & 0.51 & 6174 / 3257 & 3338 / 3041 \\
\hline$W B C$ & 0.49 & 0.49 & $6147 / 3256$ & 3334 / 3039 \\
\hline Platelets & 0.497 & 0.54 & 6176 / 3266 & 3338 / 3040 \\
\hline
\end{tabular}

Mean $\pm S D \quad 0.505 \pm 0.028 \quad 0.506 \pm 0.023$

For the 9 parameters indicated in italics (uric acid, calcium, phosphorus, sodium, ALT, AP, lipase, MCV, and platelets), comparison of the $\mathrm{CV}$ ratios between the facilities $\mathrm{A}$ and $\mathrm{B}$ revealed a difference of $>5 \%$ to $<10 \%$ of the values to each other. CV, coefficient of variation = standard deviation / mean. The values of the CV ratios are indicated in bold for the parameters where the female CV is lower than the male CV ( $=$ CV ratio $<0.5)(n=9$ of $25(36 \%)$ in facility A, and $n=10$ of $25(40 \%)$ in facility B). For facility B, the values and the respective numbers of mice of the 4 parameters calcium, chloride, phosphorus and sodium are indicated in italics, because the separate analysis of an additional smaller subgroup resulted in an inconsistent CV ratio, i.e. a CV ratio $<0.5$ for the larger subgroup shown in the table, and a CV ratio $>0.5$ for the smaller subgroup (not shown), or vice versa. Both CV ratios showed a difference of $>5 \%$ to $<10 \%$ of the values to each other. For the CV ratios with their animal numbers of facility $A / B$ indicated in bold, the separate analysis of an additional smaller subgroup resulted in a consistent CV ratio, i.e. a CV ratio either $<0.5$ or $>0.5$ both for the larger subgroup shown in the table and for the smaller subgroup (not shown). Both CV ratios showed a difference of $<5 \%$ of the values to each other. ALT, alanine aminotransferase (EC 2.6.1.2); AST, aspartate aminotransferase (EC 2.6.1.1); a-amylase (EC 3.2.1.1); $A P$, alkaline phosphatase (EC 3.1.3.1); CK, creatine kinase (EC 2.7.3.2); lipase (EC 3.1.1.3); MCV, mean corpuscular volume; RBC, red blood cell count; WBC, white blood cell count. The parameters hematocrit, mean corpuscular hemoglobin, and mean corpuscular hemoglobin concentration were not included in the study as they were subsequently calculated by using parameters directly measured.

$\mathrm{CV}$ ratios $>0.5$, and 5 of 25 with $\mathrm{CV}$ ratios $<0.5)$, whereas 9 of $25(36 \%)$ parameters showed inconsistent $\mathrm{CV}$ ratios. Comparing the $\mathrm{CV}$ ratios of a given parameter between the facilities $\mathrm{A}$ and $\mathrm{B}$, a difference of $>5 \%$ to $<$
$10 \%$ appeared for 9 of 25 (36\%) parameters analyzed, i.e. uric acid, calcium, phosphorus, sodium, alanine aminotransferase (ALT), alkaline phosphatase (AP), lipase, mean corpuscular volume (MCV), and platelets. 
This includes parameters with consistent $\mathrm{CV}$ ratios as well as with inconsistent $\mathrm{CV}$ ratios. In total, the mean \pm standard deviation of the $\mathrm{CV}$ ratios of all 25 parameters was $0.505 \pm 0.028$ in facility A, $0.506 \pm 0.023$ in facility $\mathrm{B}$, and $0.506 \pm 0.025$ for both facilities (Table 1). Therefore, no substantial sex-specific variability was evident for the overall analysis comprising all 25 clinical chemical and hematological parameters.

To investigate if the chosen data range influenced the outcome of the analysis, the data set was additionally examined by using the $99 \%$ (excluding $0.5 \%$ each of the highest and lowest values) and $90 \%$ (excluding $5 \%$ each of the highest and lowest values) data range. In total, the mean \pm standard deviation of the $\mathrm{CV}$ ratios of all 25 parameters for both facilities was $0.508 \pm 0.024$ for the $99 \%$ data range, and $0.506 \pm 0.027$ for the $90 \%$ data range. 32 of 50 parameters $(64 \%)$ showed $\mathrm{CV}$ ratios $>0.5$ (= higher female $\mathrm{CV}$ ) for the $99 \%$ data range, which was 31 of 50 parameters $(62 \%)$ for the $95 \%$ data range, and 30 of 50 parameters (60\%) for the $90 \%$ data range (Fig. 1). In addition, similar differences of the $\mathrm{CV}$ ratios of a given parameter between the facilities $\mathrm{A}$ and $\mathrm{B}$ were detected with all three data ranges. Thus, analogous results were derived with all three data ranges $(99 \%, 95 \%, 90 \%)$. The analysis of the complete data set was judged not to be informative for the aim of the current project because of the presence of data of ENU mutant animals, and therefore, was not carried out.

\section{Analysis of inbred strains and F1 hybrid mice}

A second data set of clinical chemical and hematological parameters was generated in the context of the Munich ENU mouse mutagenesis project where three studies I, II, and III were carried out in three subsequent time periods of two years each in the mouse facilities A (studies II and III) and B (study I) by using smaller groups ( $\mathrm{n}=76-247$ males and females per parameter analyzed) of group housed, native, non-mutagenized inbred (studies I and II: C3H, C57BL/6; study III: C3H, $\mathrm{BALB} / \mathrm{c}$ ) and $\mathrm{F} 1$ hybrid mice (studies I and II: B6C3F1, C3B6F1; study III: CC3F1, C3CF1) also at the age of twelve weeks.

These data sets have been previously used to investigate the phenotypic variability in the genetic backgrounds of inbred versus F1 hybrid mice. The analysis resulted in overall $\mathrm{CV}$ ratios (= F1 hybrid $\mathrm{CV} /$ (F1 hybrid CV + inbred CV)) (mean \pm standard deviation) of $0.50 \pm 0.06$ for study I, $0.37 \pm 0.09$ for study II, and $0.50 \pm 0.06$ for study III, and therefore, clearly demonstrated the possibility of major interactions between genotype and environment regarding the variability of clinical chemical and hematological parameters (Klempt et al. 2006).

For the current analysis, these data sets were reanalyzed for the aim to investigate the sex-specific variability of blood parameters in additional genetic backgrounds beside $\mathrm{C} 3 \mathrm{H}$ mice, i.e. $\mathrm{C} 57 \mathrm{BL} / 6, \mathrm{BALB} / \mathrm{c}$, and F1 hybrid mice. To exclude technical outliers,

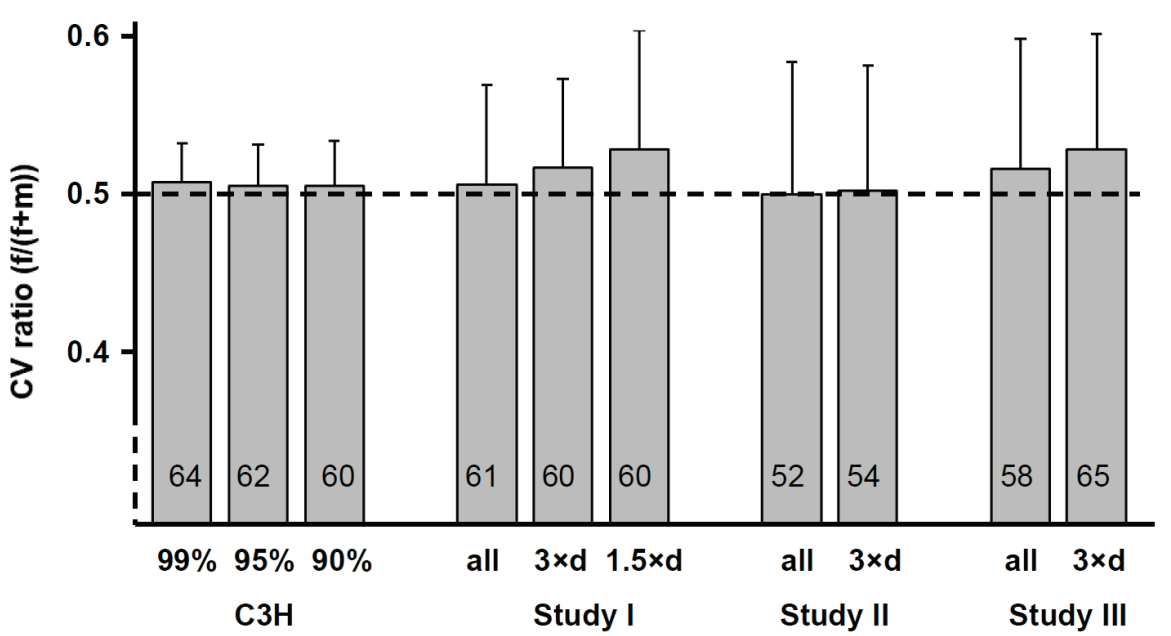

Inbred strains - F1 hybrids
Fig. 1. Mean coefficient of variation ratios (= female CV / (female CV + male CV)) \pm standard deviations of the overall analyses comprising all blood parameters. The blood parameters of $\mathrm{C} 3 \mathrm{H}$ inbred mice of the Munich ENU mouse mutagenesis project in both facilities $A$ and $B$ including 5,032-21,794 animals (males and females) per parameter examined were analyzed using the $99 \%$, $95 \%$ or $90 \%$ data range, separately for each parameter. The analysis of the blood parameters of inbred strains and the F1 hybrid mice produced thereof (study I and II: $\mathrm{C} 3 \mathrm{H}$, C57BL/6; study III: $\mathrm{C} 3 \mathrm{H}$, $\mathrm{BALB} / \mathrm{c}$ ) included 76-247 animals (males and females) per parameter examined. They were analyzed without exclusion of outliers ("all"), with exclusion of outliers $>3 \times$ distance of the first and third quartiles (" $3 \times \mathrm{d}$ "), or with exclusion of outliers $>1.5 \times$ distance of the first and third quartiles (" $1.5 \times \mathrm{d}$ ", only study I). The coefficient of variation ratios are depicted as mean \pm standard deviation for all blood parameters analyzed (see Table 1 for the $\mathrm{C} 3 \mathrm{H}$ inbred mice of the Munich ENU mouse mutagenesis project, and Table 2 for the three studies I, II and III of inbred strains and F1 hybrid mice). The number in the columns indicates the count of the parameters in \% where the female $\mathrm{CV}$ is higher than the male $\mathrm{CV}$ for the respective analysis ( $\mathrm{CV}$ ratio $>0.5$ ). 
Table 2. Coefficient of variation ratios (= female CV / (female CV + male CV)) of the blood parameters of inbred strains and F1 hybrid mice (data sets without outliers $>3 \times$ distance of the first and third quartiles)

\begin{tabular}{|c|c|c|c|c|c|c|c|c|c|c|c|c|}
\hline \multirow[t]{2}{*}{ Parameter } & \multicolumn{4}{|c|}{ Study I (C3H, C57BL/6) } & \multicolumn{4}{|c|}{ Study II (C3H, C57BL/6) } & \multicolumn{4}{|c|}{ Study III (C3H, BALB/c) } \\
\hline & IN1 & IN2 & F1A & F1B & IN1 & IN2 & F1A & F1B & IN1 & IN2 & F1A & F1B \\
\hline Cholesterol & 0.57 & 0.52 & 0.58 & 0.48 & 0.54 & 0.60 & 0.58 & 0.45 & 0.53 & 0.59 & 0.61 & 0.66 \\
\hline Glucose & 0.48 & 0.53 & 0.59 & 0.45 & 0.53 & 0.48 & 0.46 & 0.45 & 0.62 & 0.58 & 0.63 & 0.48 \\
\hline Total protein & 0.58 & 0.47 & 0.51 & 0.503 & 0.46 & 0.58 & 0.61 & 0.48 & 0.48 & 0.58 & 0.44 & 0.47 \\
\hline Triglycerides & 0.59 & 0.52 & 0.53 & 0.48 & 0.62 & 0.66 & 0.54 & 0.47 & 0.59 & 0.53 & 0.57 & 0.61 \\
\hline Urea & 0.53 & 0.48 & 0.47 & 0.60 & 0.55 & 0.55 & 0.59 & 0.52 & 0.59 & 0.54 & 0.52 & 0.58 \\
\hline Uric acid & 0.55 & 0.49 & 0.63 & 0.66 & 0.52 & 0.31 & 0.53 & 0.35 & 0.48 & 0.45 & 0.51 & 0.47 \\
\hline Ferritin & n.d. & n.d. & n.d. & n.d. & n.d. & n.d. & n.d. & n.d. & 0.38 & 0.48 & 0.39 & 0.52 \\
\hline Transferrin & n.d. & n.d. & n.d. & n.d. & n.d. & n.d. & n.d. & n.d. & 0.51 & 0.63 & 0.501 & 0.52 \\
\hline Calcium & 0.51 & 0.60 & 0.42 & 0.53 & 0.53 & 0.48 & 0.53 & 0.48 & 0.47 & n.d. & n.d. & 0.64 \\
\hline Chloride & 0.66 & 0.49 & 0.51 & 0.496 & 0.58 & 0.57 & 0.38 & 0.54 & 0.68 & n.d. & 0.43 & 0.56 \\
\hline Phosphorus & 0.53 & 0.54 & 0.49 & 0.48 & 0.51 & 0.45 & 0.42 & 0.47 & 0.49 & 0.43 & 0.61 & 0.48 \\
\hline Potassium & 0.53 & 0.56 & 0.43 & 0.43 & 0.57 & 0.39 & 0.66 & 0.45 & 0.49 & n.d. & 0.5002 & 0.499 \\
\hline Sodium & 0.59 & 0.41 & 0.496 & 0.60 & 0.55 & 0.60 & 0.43 & 0.44 & 0.71 & n.d. & 0.52 & 0.62 \\
\hline$A L T$ & 0.53 & 0.49 & 0.44 & 0.48 & 0.43 & 0.49 & 0.46 & n.d. & 0.48 & 0.46 & 0.39 & 0.49 \\
\hline$A S T$ & 0.48 & 0.43 & 0.52 & 0.52 & 0.59 & 0.48 & 0.54 & 0.33 & 0.46 & 0.57 & 0.47 & 0.57 \\
\hline$\alpha$-amylase & 0.48 & 0.53 & 0.56 & 0.47 & 0.56 & 0.60 & 0.52 & 0.53 & 0.62 & 0.55 & 0.55 & 0.68 \\
\hline$A P$ & 0.52 & 0.55 & 0.41 & 0.53 & 0.59 & 0.34 & 0.42 & 0.52 & 0.63 & 0.48 & 0.52 & 0.54 \\
\hline$C K$ & 0.51 & 0.45 & 0.54 & 0.47 & 0.55 & 0.57 & 0.62 & 0.44 & 0.53 & 0.57 & 0.502 & 0.53 \\
\hline Hemoglobin & 0.59 & 0.56 & 0.52 & 0.52 & 0.47 & 0.35 & 0.48 & 0.49 & 0.49 & 0.52 & 0.51 & 0.54 \\
\hline$M C V$ & n.d. & n.d. & n.d. & n.d. & 0.42 & 0.504 & 0.44 & 0.43 & n.d. & n.d. & n.d. & n.d. \\
\hline$R B C$ & 0.47 & 0.54 & 0.48 & 0.5001 & 0.54 & 0.503 & 0.51 & 0.55 & 0.32 & 0.56 & 0.495 & 0.54 \\
\hline$W B C$ & 0.46 & 0.46 & 0.48 & 0.57 & 0.49 & 0.44 & 0.53 & 0.61 & 0.47 & 0.51 & 0.54 & 0.53 \\
\hline Platelets & 0.55 & 0.55 & 0.59 & 0.52 & 0.38 & 0.45 & 0.51 & 0.58 & 0.52 & 0.55 & 0.53 & 0.495 \\
\hline$M e a n \pm S D$ & $\begin{array}{c}0.54 \pm \\
0.05\end{array}$ & $\begin{array}{c}0.51 \pm \\
0.05\end{array}$ & $\begin{array}{c}0.51 \pm \\
0.06\end{array}$ & $\begin{array}{c}0.51 \pm \\
0.06\end{array}$ & $\begin{array}{c}0.52 \pm \\
0.06\end{array}$ & $\begin{array}{c}0.496 \pm \\
0.09\end{array}$ & $\begin{array}{c}0.51 \pm \\
0.07\end{array}$ & $\begin{array}{c}0.48 \pm \\
0.07\end{array}$ & $\begin{array}{c}0.52 \pm \\
0.09\end{array}$ & $\begin{array}{c}0.53 \pm \\
0.05\end{array}$ & $\begin{array}{c}0.51 \pm \\
0.06\end{array}$ & $\begin{array}{c}0.55 \pm \\
0.06\end{array}$ \\
\hline $\begin{array}{c}\text { Outliers: } \\
\%(m / f)\end{array}$ & \multicolumn{4}{|c|}{$0.9 \% / 0.5 \%$} & \multicolumn{4}{|c|}{$0.9 \% / 1.1 \%$} & \multicolumn{4}{|c|}{$1.3 \% / 0.9 \%$} \\
\hline $\begin{array}{l}\text { Outliers: } \\
\% \text { affected } \\
\text { parameters } \\
(\mathrm{m} / \mathrm{f})\end{array}$ & \multicolumn{4}{|c|}{$36 \% / 24 \%$} & \multicolumn{4}{|c|}{$27 \% / 20 \%$} & \multicolumn{4}{|c|}{$39 \% / 30 \%$} \\
\hline
\end{tabular}

Study I and II: Inbred strain IN1: C3H; inbred strain IN2: C57BL/6; F1 hybrids F1A: B6C3F1; F1 hybrids F1B: C3B6F1. Study III: IN1: $\mathrm{C} 3 \mathrm{H}$; IN2: BALB/C; F1A: CC3F1; F1B: C3CF1. The number of mice (males and females) included in the analysis of the data sets without outliers $>3 \times$ distance of the first and third quartiles is (minimum-maximum (mean \pm standard deviation)) $159-247$ (196 \pm 22 ) in study I, 72-131 (101 \pm 23$)$ in study II, and 90-182 (117 \pm 30$)$ in study III per parameter examined. The number of outliers is indicated separately for males and females in \% of all values used in the study. CV, coefficient of variation = standard deviation / mean. n.d., not determined. The values of the CV ratios are indicated in bold for the parameters where the female CV is lower than the male CV $(=\mathrm{CV}$ ratio $<0.5)(\mathrm{n}=32$ of $80(40 \%)$ in study I, 38 of $83(46 \%)$ in study II, and 29 of $83(35 \%)$ in study III). In addition, values of the CV ratios are indicated in italics where the analysis of the data set without exclusion of outliers resulted in an inconsistent CV ratio, i.e. a CV ratio $<0.5$ for the analysis shown in the table, and a CV ratio $>0.5$ for the analysis of the data set without exclusion of outliers (not shown), or vice versa (with the 5 parameters of enzyme activities mostly affected). ALT, alanine aminotransferase (EC 2.6.1.2); AST, aspartate aminotransferase (EC 2.6.1.1); a-amylase (EC 3.2.1.1); AP, alkaline phosphatase (EC 3.1.3.1); CK, creatine kinase (EC 2.7.3.2); MCV, mean corpuscular volume; RBC, red blood cell count; WBC, white blood cell count. 
the data sets were analyzed with exclusion of outliers $>$ $3 \times$ distance of the first and third quartiles. The $\mathrm{CV}$ ratio (= female $\mathrm{CV} /($ female $\mathrm{CV}+$ male CV)) was determined for every parameter within each of the three studies I, II and III for each inbred strain 1 (IN1) and inbred strain 2 (IN2), and for each F1 hybrid mice 1 (F1A) and F1 hybrid mice 2 (F1B) (Table 2).

The $\mathrm{CV}$ ratios ranged from 0.41 to 0.66 in study I with $\mathrm{CV}$ ratios $<0.5$ (= lower female $\mathrm{CV}$ ) for $\mathrm{n}=32$ of $80(40 \%)$ parameters, from 0.31 to 0.66 in study II with $\mathrm{CV}$ ratios $<0.5$ for $\mathrm{n}=38$ of $83(46 \%)$ parameters, and from 0.32 to 0.71 in study III with $\mathrm{CV}$ ratios $<0.5$ for $\mathrm{n}=29$ of $83(35 \%)$ parameters (Table 2). For the studies I and II, the chi-squared test showed no significant difference $(p>0.05)$ of the detected counts of parameters with a $\mathrm{CV}$ ratio $<0.5$ and a $\mathrm{CV}$ ratio $>0.5$ compared to the hypothesis of equal numbers of parameters with a $\mathrm{CV}$ ratio $<0.5$ and a $\mathrm{CV}$ ratio $>0.5$. However, a significant difference $(p<0.01)$ appeared for study III. In total, the mean \pm standard deviation of the $\mathrm{CV}$ ratios of all parameters analyzed was $0.517 \pm 0.054$ in study I, $0.503 \pm 0.076$ in study II, and $0.528 \pm 0.070$ in study III (Fig. 1).

To investigate if the chosen data range influenced the outcome of the analysis, the data sets were additionally examined by using the complete data sets without exclusion of outliers (which has also been used in the previous analysis presented in Klempt et al. (2006), and in the case of study I with the largest group sizes of the data set, also with exclusion of outliers $>1.5 \times$ distance of the first and third quartiles. Using the complete data sets without exclusion of outliers, the mean \pm standard deviation of the $\mathrm{CV}$ ratios of all parameters analyzed was $0.507 \pm 0.060$ in study I (with $\mathrm{CV}$ ratios $<0.5$ for $\mathrm{n}=31$ of 80 (39\%) parameters), $0.501 \pm 0.080$ in study II (with CV ratios $<0.5$ for $\mathrm{n}=40$ of $84(48 \%$ ) parameters), and $0.516 \pm 0.079$ in study III (with $\mathrm{CV}$ ratios $<0.5$ for $\mathrm{n}=36$ of $85(42 \%)$ parameters $)$. Using the data set of study I with exclusion of outliers > $1.5 \times$ distance of the first and third quartiles, the mean \pm standard deviation of the $\mathrm{CV}$ ratios of all parameters analyzed was $0.528 \pm 0.072$, with $\mathrm{CV}$ ratios $<0.5$ for $\mathrm{n}=$ 32 of $80(40 \%)$ parameters (Fig. 1).

Thus, analogous overall results within the studies I, II and III were derived with all different data set ranges, i.e. without exclusion of outliers, with exclusion of outliers $>3 \times$ distance of the first and third quartiles, or with exclusion of outliers $>1.5 \times$ distance of the first and third quartiles.

\section{Joint analysis of the results of both projects}

At least higher extents of sex-specific variability in a particular parameter irrespective of genetic background and/or environmental factors are expected to result in consistent values of either $\mathrm{CV}$ ratios $<0.5$ or $\mathrm{CV}$ ratios $>0.5$ for a given parameter in both analyses shown in Table $1(\mathrm{n}=2$ separate analyses) and Table 2 ( $n=12$ separate analyses). In the search for particular parameters with consistent values in the long-term study with the high numbers of $\mathrm{C} 3 \mathrm{H}$ mice both in facility $\mathrm{A}$ and facility B shown in Table 1, as well as with the same consistent values in most of the respective 12 analyses shown in Table 2, hints for sex-specific variability may be observed for the following parameters: cholesterol ( $\mathrm{CV}$ ratio $>0.5$ in 12 of all $14(86 \%)$ analyses including all $5 \mathrm{C} 3 \mathrm{H}$ analyses), triglycerides ( $\mathrm{CV}$ ratio $>0.5$ in 12 of all 14 (86 \%) analyses including all $5 \mathrm{C} 3 \mathrm{H}$ analyses), urea (CV ratio $>0.5$ in 12 of all 14 (86\%) analyses including all $5 \mathrm{C} 3 \mathrm{H}$ analyses), and $\alpha$-amylase ( $\mathrm{CV}$ ratio $>0.5$ in 12 of all $14(86 \%)$ analyses including 4 of the $5 \mathrm{C} 3 \mathrm{H}$ analyses). The result for alanine aminotransferase (ALT, CV ratio $<0.5$ in 12 of all 13 (92\%) analyses including 4 of the $5 \mathrm{C} 3 \mathrm{H}$ analyses) was not supported by the data analysis using the data sets of study I, II and III without exclusion of outliers. No parameter showed consistent values of the $\mathrm{CV}$ ratio for all 14 separate analyses in Table 1 and Table 2.

\section{Discussion}

The retrospective analysis of the sex-specific variability of 25 blood parameters of $\mathrm{C} 3 \mathrm{H}$ inbred mice in two different mouse facilities derived from the standardized, long-term, high-throughput Munich ENU mouse mutagenesis project resulted in an overall mean of 0.51 for the ratio of the coefficient of variation (= female $\mathrm{CV} /($ female $\mathrm{CV}+$ male CV)) in both facilities. Both sexes were group housed, and females were tested without regard to the stage of the estrous cycle. The project was standardized to achieve comparable phenotypic results of a high number of animals over a long time period, but not especially for the analysis of sex-specific phenotypic variability. The $95 \%$ data range was chosen for the current study to exclude values derived from ENU mutant mice as well as technical outliers, and refers to the data range defined by the mean \pm two standard deviations.

In a meta-analysis of 293 articles including the analysis of behavioral, morphological, physiological, and 
molecular traits, group housing of mice increased the variability in both males and females by $37 \%$ (Prendergast et al. 2014). Therefore, no sex is expected to take advantage of this housing method in respect to the extent of the variability compared to the other sex. In the Munich ENU mouse mutagenesis project, both male and female mice were group housed in comparable group sizes after weaning until the phenotypic analysis including the measurement of the blood parameters took place. Normally, this works well also for $\mathrm{C} 3 \mathrm{H}$ males in the given context (group housing particularly of offspring of the same litter, no previous use in breeding, time period within the first three months of age), therefore, single housing due to aggressive behavior was carried out only exceptionally. The similar increase of the variability in group housed males and females observed by Prendergast et al. (2014) is also expected to cover the consequences of the Lee Boot effect which leads to the suppression of the estrous cycle in group housed female mice (Bind et al. 2013). In addition, this represents the housing method usually carried out when working with mice in biomedical research.

The meta-analysis did not describe particular parameters with a robust difference of the phenotypic variability between both sexes which may be used as a "positive control" to evaluate the results detected in our study. The published increase of the phenotypic variability $(=\mathrm{CV})$ within each sex by $37 \%$ in group housed animals (Prendergast et al. 2014) would effect a $\mathrm{CV}$ ratio of 0.39 or 0.61 when comparing single housed mice and group housed mice. This deviation from the hypothesized $\mathrm{CV}$ ratio of 0.5 is much higher than the deviations of the $\mathrm{CV}$ ratio of 0.5 detected in our study as the overall means of all parameters analyzed.

Comparison of the overall results of the $\mathrm{CV}$ ratios of the $\mathrm{C} 3 \mathrm{H}$ mice in the long-term experiment (means of 0.504 to 0.509 (minimum - maximum) with standard deviations of 0.022 to 0.030 (minimum maximum) for all six analyses of the $90 \%, 95 \%$ and $99 \%$ data range in both facilities) with the smaller groups of non-mutagenized $\mathrm{C} 3 \mathrm{H}$ mice in study I (means of 0.525 to 0.558 with standard deviations of 0.050 to 0.071 for all three analyses with all data, without extreme outliers and without outliers), study II (means of 0.504 and 0.522 with standard deviations of 0.061 and 0.076 for both analyses), and study III (a mean of 0.523 with standard deviations of 0.091 and 0.093 for both analyses) showed consistently higher standard deviations for the studies I, II and III with the small groups of animals. This is thought to be caused not by the slight difference in the panel of blood parameters which were available for the separate studies, but by the number of examined animals by itself.

Comparison of the $\mathrm{CV}$ ratios on the basis of the identical genetic background, i.e. of the five groups of $\mathrm{C} 3 \mathrm{H}$ mice (long-term study in facility A, long-term study in facility B, study I, study II, study III) for a given parameter may indicate that the sex-specific variability may distinctly vary due to interacting factors. As this was observed also between facility A and facility B with high numbers of mice involved, the same effect may be expected in experiments with low group sizes which are normally used in biomedical research. This refers to the result which was previously received in the investigation of the variability of phenotypic parameters in the inbred versus F1 hybrid genetic background (Klempt et al. 2006).

In summary, the overall analysis comprising all 25 clinical chemical and hematological parameters of the standardized, long-term analysis of a high number of group housed, young adult, twelve-week-old C3H inbred mice showed no evidence for substantial sex-specific variability. The results may provide a basis for the examination of sex-specific variability in particular blood parameters.

\section{Conflict of Interest}

There is no conflict of interest.

\section{Acknowledgements}

No funding was obtained for this study.

\section{References}

AIGNER B, RATHKOLB B, KLAFTEN M, SEDLMEIER R, KLEMPT M, WAGNER S, MICHEL D, MAYER U, KLOPSTOCK T, HRABĚ DE ANGELIS M, WOLF E: Generation of N-ethyl-N-nitrosourea-induced mouse mutants with deviations in plasma enzyme activities as novel organ-specific disease models. Exp Physiol 94: 412-421, 2009. https://doi.org/10.1113/expphysiol.2008.045864

AIGNER B, RATHKOLB B, KLEMPT M, WAGNER S, MICHEL D, HRABĚ DE ANGELIS M, WOLF E: N-ethyl$\mathrm{N}$-nitrosourea mutagenesis produced a small number of mice with altered plasma electrolyte levels. J Biomed Sci 16: 53, 2009. https://doi.org/10.1186/1423-0127-16-53 
AIGNER B, RATHKOLB B, KLEMPT M, WAGNER S, MICHEL D, KLAFTEN M, LAUFS J, SCHNEIDER B, SEDLMEIER R, HRABĚ DE ANGELIS M, WOLF E: Generation of N-ethyl-N-nitrosourea-induced mouse mutants with deviations in hematological parameters. Mamm Genome 22: 495-505, 2011. https://doi.org/10.1007/s00335-011-9328-4

BEERY AK, ZUCKER I: Sex bias in neuroscience and biomedical research. Neurosci Biobehav Rev 35: 565-572, 2011. https://doi.org/10.1016/j.neubiorev.2010.07.002

BIND RH, MINNEY SM, ROSENFELD S, HALLOCK RM: The role of pheromonal responses in rodent behavior: future directions for the development of laboratory protocols. J Am Assoc Lab Anim Sci 52: 124-129, 2013.

CLAYTON JA, COLLINS FS: Policy: NIH to balance sex in cell and animal studies. Nature 509: 282-283, 2014. https://doi.org/10.1038/509282a

GAILUS-DURNER V, FUCHS H, BECKER L, BOLLE I, BRIELMEIER M, CALZADA-WACK J, ELVERT R, EHRHARDT N, DALKE C, FRANZ TJ, GRUNDNER-CULEMANN E, HAMMELBACHER S, HOLTER SM, HOLZLWIMMER G, HORSCH M, JAVAHERI A, KALAYDJIEV SV, KLEMPT M, KLING E, KUNDER S, LENGGER C, LISSE T, MIJALSKI T, NATON B, PEDERSEN V, PREHN C, PRZEMECK G, RACZ I, REINHARD C, REITMEIR P, SCHNEIDER I, SCHREWE A, STEINKAMP R, ZYBILL C, ADAMSKI J, BECKERS J, BEHRENDT H, FAVOR J, GRAW J, HELDMAIER G, HOFLER H, IVANDIC B, KATUS H, KIRCHHOF P, KLINGENSPOR M, KLOPSTOCK T, LENGELING A, MULLER W, OHL F, OLLERT M, QUINTANILLA-MARTINEZ L, SCHMIDT J, SCHULZ H, WOLF E, WURST W, ZIMMER A, BUSCH DH, HRABĚ DE ANGELIS M: Introducing the German Mouse Clinic: open access platform for standardized phenotyping. Nat Methods 2: 403-404, 2005. https://doi.org/10.1038/nmeth0605-403

HRABĚ DE ANGELIS M, FLASWINKEL H, FUCHS H, RATHKOLB B, SOEWARTO D, MARSCHALL S, HEFFNER S, PARGENT W, WUENSCH K, JUNG M, REIS A, RICHTER T, ALESSANDRINI F, JAKOB T, FUCHS E, KOLB H, KREMMER E, SCHAEBLE K, ROLLINSKI B, ROSCHER A, PETERS C, MEITINGER T, STROM T, STECKLER T, HOLSBOER F, KLOPSTOCK T, GEKELER F, SCHINDEWOLF C, JUNG T, AVRAHAM K, BEHRENDT H, RING J, ZIMMER A, SCHUGHART K, PFEFFER K, WOLF E, BALLING R: Genome-wide, large-scale production of mutant mice by ENU mutagenesis. Nat Genet 25: 444-447, 2000. https://doi.org/10.1038/78146

HRABĚ DE ANGELIS M, MICHEL D, WAGNER S, BECKER S, BECKERS J: Chemical mutagenesis in mice. In: The mouse in biomedical research - v1 History, wild mice, and genetics. FOX JG, BARTHOLD SW, DAVISSON MT, NEWCOMER CE, QUIMBY FW, SMITH AL (Eds.). Academic Press, Burlington, MA, 2007, pp 225-260. https://doi.org/10.1016/B978-012369454-6/50024-8

ITOH Y, ARNOLD AP: Are females more variable than males in gene expression? Meta-analysis of microarray datasets. Biol Sex Differ 6: 18, 2015. https://doi.org/10.1186/s13293-015-0036-8

KLEMPT M, RATHKOLB B, FUCHS E, HRABĚ DE ANGELIS M, WOLF E, AIGNER B: Genotype-specific environmental impact on the variance of blood values in inbred and F1 hybrid mice. Mamm Genome 17: 93-102, 2006. https://doi.org/10.1007/s00335-005-0119-7

MOGIL JS, CHANDA ML: The case for the inclusion of female subjects in basic science studies of pain. Pain 117: 1-5, 2005. https://doi.org/10.1016/j.pain.2005.06.020

NICKLAS W, BANEUX P, BOOT R, DECELLE T, DEENY AA, FUMANELLI M, ILLGEN-WILCKE B: Recommendations for the health monitoring of rodent and rabbit colonies in breeding and experimental units. Lab Anim 36: 20-42, 2002. https://doi.org/10.1258/0023677021911740

PRENDERGAST BJ, ONISHI KG, ZUCKER I: Female mice liberated for inclusion in neuroscience and biomedical research. Neurosci Biobehav Rev 40: 1-5, 2014. https://doi.org/10.1016/j.neubiorev.2014.01.001

RATHKOLB B, DECKER T, FUCHS E, SOEWARTO D, FELLA C, HEFFNER S, PARGENT W, WANKE R, BALLING R, HRABĚ DE ANGELIS M, KOLB HJ, WOLF E: The clinical-chemical screen in the Munich ENU Mouse Mutagenesis Project: screening for clinically relevant phenotypes. Mamm Genome 11: 543-546, 2000. https://doi.org/10.1007/s003350010104

RATHKOLB B, FUCHS E, KOLB HJ, RENNER-MULLER I, KREBS O, BALLING R, HRABĚ DE ANGELIS M, WOLF E: Large-scale N-ethyl-N-nitrosourea mutagenesis of mice - from phenotypes to genes. Exp Physiol 85: 635-644, 2000. https://doi.org/10.1017/S0958067000020947 
RATHKOLB B, KLEMPT M, SABRAUTZKI S, MICHEL D, KLAFTEN M, LAUFS J, SEDLMEIER R, HANS W, FUCHS H, MUCKENTHALER MU, HORSCH M, CAMPAGNA DR, FLEMING M, HRABĚ DE ANGELIS M, WOLF E, AIGNER B: Screen for alterations of iron related parameters in N-ethyl-N-nitrosourea-treated mice identified mutant lines with increased plasma ferritin levels. Biometals 28: 293-306, 2015. https://doi.org/10.1007/s10534-015-9824-1

SANDBERG K, UMANS JG, GEORGETOWN CONSENSUS CONFERENCE WORK G: Recommendations concerning the new U.S. National Institutes of Health initiative to balance the sex of cells and animals in preclinical research. FASEB J 29: 1646-1652, 2015. https://doi.org/10.1096/fj.14-269548

VARHOLICK JA, BAILOO JD, PALME R, WURBEL H: Phenotypic variability between Social Dominance Ranks in laboratory mice. Sci Rep 8: 6593, 2018. https://doi.org/10.1038/s41598-018-24624-4 